\title{
OS CONTORNOS TEÓRICOS DO FUNDAMENTO DA DIGNIDADE DA PESSOA HUMANA E SUA EFICÁCIA NO ÂMBITO DO DIREITO PRIVADO
}

\begin{abstract}
RESUMO
A dignidade em sentido vulgar traduz honradez, virtude, valor ou qualidade moral que induz ao respeito. O princípio da dignidade da pessoa humana, previsto no art. $1^{\circ}$, III da Constituição Federal de 1988, é valor edificado ao longo da história da humanidade e sustentáculo do ordenamento jurídico brasileiro, afastando a ideia apriorística. Contudo, compreender o seu alcance e identificar o seu elemento nuclear não é tarefa fácil, mas sim imperiosa para evitar a sua banalização ou invocação
\end{abstract}

${ }^{1}$ Doutora em Direito - Efetividade do Direito, subárea Direito Civil pela Pontifícia Universidade Católica de São Paulo (2016). Mestre em Direito das Obrigações pela Universidade Estadual Paulista Júlio de Mesquita Filho - Campus Franca/SP (2003). Graduação em Ciências Sociais e Jurídicas Aplicadas - Faculdades Integradas Toledo Araçatuba (1998). Advogada. Professora Titular da disciplina Direito Civil II na Faculdade de Direito de Franca. Professor de Ensino Superior III-E da Faculdade de Tecnologia de Mococa - Fatec Mococa (desde agosto de 2008) e Diretora da Faculdade de Tecnologia de Mococa (Gestão 2017/2021). Experiência na área de Direito Civil, Direito Processual Civil, Direito do Consumidor, Teoria Geral do Direito e Direito Empresarial. Coordenadora Acadêmica do Curso de Direito na Faculdade de Ciências Agrárias e Sociais - FAIT (2002/2005). Coordenadora do Núcleo de Prática Jurídica - UNIFEG (2007 a 2011), conforme Portaria 006/2007. Membro do Núcleo Docente Estruturante - UNIFEG (2009/2011). Assistente Técnico Administrativo I (Cargo em Confiança 10/2010 a 07/2017) na Faculdade de Tecnologia de Mococa. Professor do Centro Universitário da Fundação Educacional Guaxupé - UNIFEG (2005/2012 e 2014/2017). Professora na Faculdade de Ciências Agrárias e Sociais - FAIT (2002/2007). 
indevida na efetividade da atividade jurisdicional. Diante desse cenário, este artigo, sem a pretensão de esgotar o tema, apresenta os contornos teóricos da dignidade da pessoa humana propostos por Jorge Reis Novais e Ingo Wolfgand Sarlet e justifica, através da perspectiva teleológica, seu fundamento e sua eficácia no âmbito do direito privado. A identificação do elemento nuclear do princípio da dignidade da pessoa permite garantir e promover a dignidade das pessoas bem como repelir qualquer forma de discriminação ou degradação.

Palavras-chave: dignidade, dignidade da pessoa humana, direito privado.

\begin{abstract}
Dignity in the vulgar sense translates honesty, virtue, value or moral quality that induces respect. The principle of the dignity of the human person, as seen in art. $1^{\circ}$, III of the Federal Constitution of 1988, is a value built throughout the history of humanity and sustaining the Brazilian legal system, away from the a priori idea. However, understanding its scope and identifying its nuclear element is not an easy task, but it is imperative to avoid its banalization or improper invocation of the effectiveness of the jurisdictional activity. In view of this scenario, this article, without pretending to exhaust the theme, presents the theoretical contours of the dignity of the human person proposed by Jorge Reis Novais and Ingo Wolfgand Sarlet and justifies, through the teleological perspective, its foundation and its effectiveness in the field of law private. The identification of the core element of the principle of the dignity of the person allows to guarantee and promote the dignity of the people as well as to repel any form of discrimination or degradation.
\end{abstract}

Keywords: dignity, dignity of the human person, private law.

\title{
INTRODUÇÃO
}

A preocupação com a valorização humana é recente na história da humanidade. Inicialmente, as lutas e os desafios do homem centravamse na sobrevivência e nas questões referentes às supremacias econômica, étnica ou territorial. A sociedade contemporânea é marcada por novos desafios e conquistas, pois há o reconhecimento de que o homem necessita tanto da produção social quanto da espiritual para que se desenvolva de forma integral e integrado na sociedade em que está inserido.

Para Gustav Radbruch, as ideias relativas à humanidade seguem três direções "[...] amor ao homem, contra toda a crueldade desumana; dignidade do homem, contra toda humilhação do homem; formação do homem, contra todo aniquilamento desumano da cultura."2

Do mesmo modo, a dignidade ganha novos contornos com o reconhecimento em Declarações Internacionais e sistemas constitucionais positivos em vários países. A partir desse momento inicia-se a formula-

${ }^{2}$ RADBRUCH, Gustav. Introdução à filosofia do direito. São Paulo: Método. 2014. p. 83. 
ção jurídica do princípio da dignidade da pessoa humana e revela a sua condição de princípio jurídico fundamental.

A Carta das Nações Unidas em 1945 ratificada pelo governo brasileiro estabelece no preâmbulo a preservação das gerações vindouras e reafirma "a fé nos direitos fundamentais do homem, na dignidade e no valor do ser humano, na igualdade de direito dos homens e das mulheres". ${ }^{3}$ Em seguida, a Declaração Universal dos Direitos Humanos, em 1948, reconhece a dignidade inerente a todos os membros da família humana e seus direitos iguais e inalienáveis sob o fundamento da liberdade, da justiça e da paz no mundo. Ademais, o artigo 1 estabelece, in verbis que "Todos os homens nascem livres e iguais em dignidade e direitos. São dotados de razão e consciência e devem agir em relação aos outros com espírito de fraternidade". 4

A Constituição da República italiana de 1947 em seu artigo 3, primeira parte estabelece que "Todos os cidadãos têm a mesma dignidade social e são iguais perante a lei, sem discriminação de sexo, de raça, de língua, de religião, de opiniões políticas, de condições pessoais e sociais." e do mesmo modo a Constituição alemã no artigo 1.1 trata da intangibilidade da dignidade da pessoa humana, in verbis "A dignidade da pessoa humana é intangível. Respeitá-la e protegê-la é obrigação de todo o poder público."

No Brasil, tanto a Constituição de 1967 quanto a Emenda Constitucional de 1/1969 previa no artigo 157 e 160, respectivamente, no âmbito da Ordem Econômica e Social a valorização do trabalho como condição da dignidade humana. Todavia, a dimensão de fundamento da ordem constitucionalizada ocorre somente com a Constituição Federal de 1988 (art. $1^{\circ}$, III)..$^{5}$

3 DECLARAÇÃO DAS NAÇÕES UNIDAS. Disponível em http://www.planalto.gov.br/ccivil_03/decreto/1930-1949/d19841.htm. Acesso em 27 fev. 2017.

4 DECLARAÇÃO UNIVERSAL DOS DIREITOS DO HOMEM. Disponível em http://www.dhnet.org.br/direitos/deconu/textos/integra.htm. Acesso em 27 fev. 2017.

${ }^{5} \mathrm{E}$, ainda, o art. 227 da CF/88 estabelece que "É dever da família, da sociedade e do Estado assegurar à criança, ao adolescente e ao jovem, com absoluta prioridade, o direito à vida, à saúde, à alimentação, à educação, ao lazer, à profissionalização, à cultura, à dignidade, ao respeito, à liberdade e à convivência familiar e comunitária, além de colocá-los a salvo de toda forma de negligência, discriminação, exploração, violência, crueldade e opressão."; o art. 226 da CF/88 dispõe que "A família, base da sociedade, tem especial proteção do Estado. $\$ 7^{\circ}$ Fundado nos princípios da dignidade da pessoa humana e da paternidade responsável, o planejamento familiar é livre decisão do casal, competindo ao Estado propiciar recursos educacionais e científicos para o exercício desse direito, vedada 
Miguel Reale destaca, na Exposição de Motivos do Anteprojeto do Código Civil, a importância de superar o individualismo do Código Civil de 1916 e reconhecer "cada vez mais que o Direito é social em sua origem e em seu destino, impondo a correlação concreta e dinâmica dos valores coletivos com individuais, para que a pessoa humana seja preservada sem privilégios e exclusivismo, numa ordem global de comum participação".6

Para Rosa Maria Andrade Nery e Nelson Nery a dignidade humana confere experiência jurídica em duas vertentes, ou seja, "(a) coloca a pessoa como protagonista de situações jurídicas de direitos fundamentais e (b) coloca o Estado como protagonista de garantir à pessoa o exercício pleno dessa posição jurídica, ainda que essa experiência particular possa vir a ser contraposta ao Poder Público". ${ }^{7}$

Diante deste cenário, este artigo, sem a pretensão de esgotar o tema, apresenta os contornos teóricos da dignidade da pessoa humana propostos por Jorge Reis Novais e Ingo Wolfgand Sarlet com o objetivo de delinear o seu elemento nuclear para evitar o uso indiscriminado ou a invocação desnecessária desse princípio previsto no art. $1^{\circ}$, III da Constituição Federal de 1988, bem como justificar o fundamento da dignidade da pessoa humana e sua eficácia no âmbito do direito privado.

\section{2 \\ A DIGNIDADE COMO INTEGRIDADE HUMANA E COMO IGUAL DIGNIDADE NA CONCEPÇÃO DE JORGE REIS NOVAIS}

Jorge Reis Novais, ao discorrer sobre a dignidade como integridade humana, destaca a importância em estabelecer, incialmente, a diferença entre a dignidade (dignitas) de origem romana e grega e a dignidade humana ou da pessoa humana, tratada pelo autor como dignidade adjetivada, para que seja possível identificar a dignidade da pessoa humana enquanto dever jurídico e sua recepção jurídico-constitucional.

qualquer forma coercitiva por parte de instituições oficiais ou privadas." e o art. art. 230 da CF/88 prescreve que "A família, a sociedade e o Estado têm o dever de amparar as pessoas idosas, assegurando sua participação na comunidade, defendendo sua dignidade e bem-estar e garantindo-lhes o direito à vida."

${ }^{6}$ REALE, Miguel. História do novo Código Civil. São Paulo: RT, 2005. p. 68.

7 NERY, Rosa Maria de Andrade; NERY, Nelson. Instituições de direito civil: parte geral. v. I, t. I. São Paulo: RT, 2015. p. 322. 
Nos ensinamentos do autor a dignidade não adjetivada traduz a dignitas romana ${ }^{8}$, ou seja, o valor, a honra ou o apreço e é caracterizada pelo atributo condicional, contingente e gradual bem como revela a qualidade ou o status social que toca a pessoa em determinada circunstância ou posição que ela ocupa na sociedade em que se encontra inserida. ${ }^{9}$

Nesse sentido, a dignidade é "vocábulo que designa honraria ou distinção, consiste em cargo ou título de alta graduação que é conferida a uma pessoa. [...] No sentido vulgar, é a qualidade moral da pessoa, suporte da boa fama em que ela é conceituada". ${ }^{10}$

Já a dignidade adjetivada, ou seja, a dignidade da pessoa humana é inerente à condição humana sendo, portanto, incondicional, inalienável e imperdível. ${ }^{11}$ Nas palavras do autor ela está "associada à universalidade e à igualdade, ao reconhecimento igual devido a qualquer pessoa pelo facto de ser pessoa, enquanto algo permanente, intrínseco ou consubstancial à pessoa, irrecusável e indisponível". ${ }^{12}$

Desse modo, a dignidade da pessoa humana de forma igualitária a todas as pessoas é indissociável da ideia de igual dignidade, pois é a partir do seu reconhecimento no plano constitucional que se repele o estatuto elevado, uma vez que a dignidade é um valor intrínseco à pessoa. ${ }^{13}$

Nesse contexto, o autor aduz que o pensamento cristão contribui no reconhecimento da igual dignidade sob o fundamento de que o homem é uma criatura feita por Deus à sua imagem e semelhança e por essa razão cada ser humano é dotado de dignidade independentemente do seu estatuto ou de característica particular. ${ }^{14}$ Essa potencialidade mostra que "um

\footnotetext{
${ }^{8}$ NOVAIS, JORGE REIS. A dignidade da pessoa humana: dignidade e direitos fundamentais. v. I. Coimbra: Almedina. 2016. p. 33-34. O autor esclarece que "Na Roma antiga, dignitas surgia intimamente ligada à especificidade de um status, significando a honra e o especial respeito, deferência e consideração devidos a alguém por força do estatuto pessoal superior que lhe era socialmente reconhecido ou que lhe era circunstancialmente atribuídos, por exemplo pelo fato de exercer uma magistratura ou pela investidura num cargo público em si mesmos objectivamente considerados dignos" (grifos do autor) p. 34 .

9 ibidem., p. 31-34.

${ }^{10}$ FRANÇA, Limongi R. Enciclopédia Saraiva. v. 25. São Paulo: Saraiva, 1977. p. 38.

${ }^{11}$ NOVAIS, JORGE REIS. A dignidade da pessoa humana: dignidade e direitos fundamentais. v. I. Coimbra: Almedina. 2016. p. 31-34.

12 ibidem., p. 33-34.

${ }^{13}$ NOVAIS, JORGE REIS. A dignidade da pessoa humana: dignidade e direitos fundamentais. v. I. Coimbra: Almedina. 2016. p. 37-38.

14 ibidem., p. 39-41.
} 
estatuto moral qualificado, derivado do acto da criação divina, deveria prevalecer sobre quaisquer diferenças particulares." 15

Do mesmo modo, o autor apresenta as contribuições do período do renascimento e iluminismo para a reconstrução filosófica da dignidade com o objetivo de traçar os contornos do alcance da dignidade da pessoa humana.

O período do renascimento, apoiado nas ideias de Pico Della Mirandola, identifica a especial capacidade dos homens e a dignidade da pessoa humana, que revela a liberdade de decisão do homem, ou seja, de decidir o próprio destino. Já o período do iluminismo, amparado nas concepções de Blaise Pascal, Samuel Pufendorf e Immanuel Kant, considera a dignidade independentemente da crença religiosa, pois ela está alicerçada na capacidade do homem atuar de forma racional na autodeterminação e na responsabilidade moral. ${ }^{16}$

Nas palavras do autor:

[...] apesar da origem cristã da ideia de igual dignidade, foi esta potencial depuração e emancipação filosófica do conceito de dignidade relativamente aos dogmas do criacionismo divino produzida pelo pensamento kantiano que possibilitaria, mais tarde, por um lado, a juridificação do conceito - ou seja, a transição de dever virtuoso a dever jurídico - e por outro lado, a sua recepção jurídico-constitucional por parte de um Estado laico e de um Direito Constitucional inclusivo e não confessional. ${ }^{17}$

Nessa dinâmica, o autor pontifica que a dignidade da pessoa humana protegida constitucionalmente traduz a dignidade como respeito da humanidade intrínseca da pessoa, a dignidade da pessoa como sujeito e a dignidade como igualdade. ${ }^{18}$

A dignidade como respeito da humanidade intrínseca da pessoa considera a pessoa de forma individual enquanto sujeito autônomo e responsável por suas condutas, pois age de forma racional ao avaliar seu comportamento nas questões que envolvem os seus direitos e obrigações, ou seja, exerce de forma responsável a sua autodeterminação. ${ }^{19}$

\footnotetext{
15 ibidem., p. 41.

16 ibidem., p. 42-43.

17 ibidem., p. 45-45.

18 ibidem., p. 101-142.

${ }^{19}$ NOVAIS, JORGE REIS. A dignidade da pessoa humana: dignidade e inconstitucionalidade. v. II. Coimbra: Almedina. 2016. p. 102-103.
} 
Para Jorge Reis Novais a dignidade da pessoa como sujeito se desenvolve quando são proporcionadas condições que garantam à pessoa exercer sua autonomia, tanto na esfera pública quanto privada, o exercício de sua autonomia, o controle de sua identidade, a viabilização de meios para que possa se desenvolver enquanto pessoa e afastar qualquer possibilidade de submetê-la à condição de objeto ou coisa, ou seja, o desenvolvimento se dá nos planos da

(i) proscrição de subjugação e de exclusão, com a garantia da essencial autonomia da pessoa;

(ii) inadmissibilidade correlativa de degradação da pessoa como objeto ou coisa;

(iii) proibição de alienação identitária e de devassa humilhante, com a garantia do controle do próprio sobre a sua identidade, o seu reino interior e sua apresentação pública;

(iv) inaceitabilidade da incapacitação da pessoa, a quem devem ser garantidas as condições materiais e a educação que lhe permitam afirmar-se, ou desenvolver-se na medida de suas capacidades, como sujeito da própria vida. ${ }^{20}$ (grifos do autor)

E, a dignidade como igualdade implica a aceitação da diferença e o reconhecimento público, pois requer tanto a igualdade de direito e tratamento quanto a erradicação de qualquer forma de discriminação ou nas palavras do autor, "atitudes que incutam, perpetuem ou admitam a ideia de que há, numa comunidade, capitis deminutiones, cidadãos de primeira e de segunda" 21 . Nesse contexto, a garantia de igual dignidade reforça a imperiosa necessidade de igual respeito e consideração de interesses.

Para o autor, a projeção dos efeitos jurídicos do princípio da dignidade da pessoa humana envolve vários sentidos e diferentes funções, a saber:

(i) [...] critério ou padrão geral de conformação do sentido do relacionamento entre o indivíduo e poderes públicos num Estado de Direito;

(ii) [...] fundamento material dos direitos fundamentais especificamente elencados e como critério de interpretação e integração das normas constitucionais jusfundamentais, incluindo na qualidade de critério de recepção constitucional de direitos fundamentais não expressamente enumerados no texto constitucional;

(iii) [...] critério de delimitação interpretativa do conteúdo protegido dos direitos fundamentais e como critério de invalidação

\footnotetext{
20 ibidem., p. 101-107.

21 ibidem., p. 136.
} 
constitucional de eventuais justificações que os poderes públicos invocam para restringir os direitos fundamentais;

(iv) [...] fundamento e referência genética dos princípios constitucionais estruturantes de Estado de Direito que vinculam toda a actuação do Estado e são aplicáveis enquanto limites aos limites dos direitos fundamentais;

(v) [...] critério de preenchimento e conformação do conteúdo essencial dos direitos fundamentais;

(vi) [...] limite autónomo e parâmetro de controlo de constitucionalidade das restrições aos direitos fundamentais. ${ }^{22}$

A partir dessa análise, é possível identificar que o elemento nuclear da dignidade da pessoa humana é a liberdade, a autonomia e o bemestar do cidadão para que a pessoa possa exercer o seu papel social apoiada na autodeterminação.

Desse modo, o ordenamento jurídico afasta a aplicação da dignidade não adjetivada, pois, na Constituição Federal de 1988, o fundamento da dignidade da pessoa humana traduz o respeito à pessoa nas dimensões físicas e existenciais, por ser inerente à humanidade de cada um para que a pessoa possa desenvolver de forma integral e integrada em igualdade de oportunidade.

Nesse sentido, tem-se o posicionamento do STF no tocante à dignidade adjetivada ou dignidade da pessoa humana:

A 'escravidão moderna' é mais sutil do que a do século XIX e o cerceamento a liberdade pode decorrer de diversos constrangimentos econômicos e não necessariamente físicos. Priva-se alguém de sua liberdade e de sua dignidade tratando-o como coisa, e não como pessoa humana, o que pode ser feito não só mediante coação, mas também pela violação intensa e persistente de seus direitos básicos, inclusive do direito ao trabalho digno. A violação do direito ao trabalho digno impacta a capacidade da vítima de realizar escolhas segundo a sua livre determinação. Isso também significa 'reduzir alguém a condição análoga à de escravo'." (Inq 3.412, rel. p/ o ac. min. Rosa Weber, julgamento em 29-3-2012, Plenário, DJE de 12-11-2012.) (grifo meu)

A Lei 8.899/1994 é parte das políticas públicas para inserir os portadores de necessidades especiais na sociedade e objetiva a igualdade de oportunidades e a humanização das relações sociais, em cumprimento aos fundamentos da República de cidadania e dignidade da pessoa humana, o que se concretiza pela definição

22 NOVAIS, JORGE REIS. A dignidade da pessoa humana: dignidade e inconstitucionalidade. v. II. Coimbra: Almedina. 2016. p. 137. 
de meios para que eles sejam alcançados. (ADI 2.649, Rel. Min. Cármen Lúcia, julgamento em 8-5-2008, Plenário, DJE de 17-102008.) (grifo meu)

Nessa ordem, resta afastada a banalização do fundamento da dignidade da pessoa humana, pois importa identificar na situação fática apresentada o elemento nuclear da dignidade da pessoa humana.

\section{AS DIMENSÕES DA DIGNIDADE DA PESSOA HUMANA PROPOSTAS POR INGO WOLFGANG SARLET}

Ingo Wolfgang Sarlet explicita as múltiplas dimensões da dignidade da pessoa humana; ele aborda as dimensões ontológica, comunicativa e relacional, histórico-cultural e a dupla dimensão negativa e prestacional. $^{23}$

Sob o prisma da dimensão ontológica, a dignidade decorre da própria condição humana e inerente a toda pessoa, pois é valor absoluto e insubstituível. Nessa dimensão, o autor salienta que "[...] a dignidade evidentemente não existe apenas onde é reconhecida pelo Direito e, na medida em que este a reconhece, já que - pelo menos em certo sentido constitui dado prévio, no sentido de preexistente e anterior a toda a experiência especulativa". ${ }^{24}$

A dimensão comunicativa e relacional da dignidade preconiza que cada pessoa é dotada de dignidade, e todas as pessoas que convivem em comunidade são iguais em dignidades e direitos. É nessa perspectiva que floresce o dever geral de respeito pela pessoa, ou seja, as relações intersubjetivas devem ser marcadas pelo respeito e consideração mútuos. $^{25}$

A perspectiva histórico-cultural indica que a dignidade da pessoa decorre do desenvolvimento da própria sociedade, isto é, "[...] fruto do trabalho de diversas gerações e da humanidade em seu todo." ${ }^{26}$ Para o

${ }^{23}$ SARLET, Ingo Wolfgang. Dimensões da dignidade: ensaios de filosofia do direito e direito constitucional. Porto Alegre: Livraria do Advogado. 2013. p. 15-43.

${ }^{24}$ ibidem., p. 21.

25 ibidem., p. 23-27. Acrescenta o autor que a dignidade na dimensão relacional e comunicativa constitui uma categoria da co-humanidade de cada indivíduo. Ademais, "[...] a noção da dignidade como produto do reconhecimento da essencial unidade de cada pessoa humana e do fato de esta ser credora de um dever igual respeito e proteção no âmbito da comunidade humana". (p.27)

26 ibidem., p. 28. 
autor, não se pode confundir dignidade da pessoa humana e dignidade humana, pois esta se refere à humanidade, enquanto aquela constitui atributo da pessoa humana individualmente considerada. A distinção se torna relevante para afastar a ideia que de que o conceito de dignidade seja vago ou apriorístico.

A Constituição Federal de 1988, nos ensinamentos de Ingo Wolfgang Sarlet, acolhe a distinção, pois consagra no art. $1^{\circ}$, III, dentre os fundamentos da República Federativa do Brasil, o princípio da dignidade da pessoa humana e não da dignidade da humanidade. Resta, assim, demonstrado o conteúdo concreto e determinado do princípio da dignidade da pessoa humana tanto na conduta do Estado quanto no comportamento de cada pessoa na sociedade em que está inserida.

$\mathrm{E}$, por fim, a dupla dimensão negativa (limite) e prestacional (tarefa) da dignidade. Esta indica o respeito e as medidas jurídicas para reconhecer, proteger, tutelar e garantir a efetividade do princípio da dignidade da pessoa humana; aquela consiste em impedir a coisificação da pessoa, bem como atitudes que violem a dignidade humana. Segundo Ingo Wolfgang Sarlet, esta dimensão

Assume particular relevância a constatação de que a dignidade da pessoa humana é simultaneamente limite e tarefa dos poderes estatais e, no nosso sentir, da comunidade em geral, de todos e de cada um, condição dúplice esta que também aponta para uma paralela e conexa dimensão defensiva e prestacional da dignidade. Como limite, a dignidade implica não apenas que a pessoa não pode ser reduzida à condição de mero objeto da ação própria e de terceiros, mas também o fato de a dignidade gerar direitos fundamentais (negativos) contra atos que a violem ou a exponham a graves ameaças. Como tarefa, da previsão constitucional (explícita ou implícita) da dignidade da pessoa humana, dela decorrem deveres concretos de tutela por parte dos órgãos estatais, no sentido de proteger a dignidade de todos, assegurando-lhe também por meio de medidas positivas (prestações) o devido respeito e promoção. $^{27}$

O autor apresenta as várias dimensões da dignidade da pessoa humana e identifica como elemento nuclear a autonomia e o direito de

\footnotetext{
${ }^{27}$ SARLET, Ingo Wolfgang. Dimensões da dignidade: ensaios de filosofia do direito e direito constitucional. Porto Alegre: Livraria do Advogado. 2013. p. 32; SARLET, Ingo Wolfgang. Dignidade (da Pessoa) humana e

direitos fundamentais na Constituição Federal de 1988. Porto Alegre: Livraria do Advogado. 2015. p. 93.
} 
autodeterminação da pessoa ou de cada pessoa. ${ }^{28} \mathrm{E}$, propõe o conceito jurídico de forma analítica da dignidade da pessoa humana:

[...] a qualidade intrínseca e distintiva reconhecida em cada ser humano o que o faz merecedor do mesmo respeito e consideração por parte do Estado e da comunidade, implicando, neste sentido, um complexo de direitos e deveres fundamentais que assegurem a pessoa tanto contra todo e qualquer ato de cunho degradante e desumano, como venham a lhe garantir as condições existenciais mínimas para uma vida saudável, além de propiciar e promover sua participação ativa e corresponsável nos destinos da própria existência e da vida em comunhão com os demais seres humanos. ${ }^{29}$

Nessa conjectura, a dignidade da pessoa humana como atributo inerente do ser humano não é concedida pelo ordenamento jurídico. Ela é norma (valor, princípio e regra fundamental) reconhecida, respeitada, protegida e até mesmo promovida na ordem jurídico-constitucional. ${ }^{30}$

Nota-se, portanto, a dificuldade de se estabelecer o conceito jurídico da dignidade em razão das múltiplas dimensões apresentadas. Todavia, constata-se que a dignidade da pessoa humana é valor edificado, ao

\footnotetext{
${ }^{28}$ SARLET, Ingo Wolfgang A eficácia dos direitos fundamentais. Porto Alegre: Livraria do Advogado, 2015. p.103; SARLET, Ingo Wolfgang. As dimensões da dignidade humana: construindo uma compreensão jurídico-constitucional necessária e possível. In: Dimensões da dignidade: ensaios de filosofia do direito e direito constitucional. Porto Alegre: Livraria do Advogado. 2013. p. 15-43. Pondera o autor que "[...] um dos papéis centrais do Direito e da Filosofia do Direito é o de assegurar, por intermédio de uma adequada construção

e compreensão da noção de dignidade da pessoa humana, a superação de qualquer visão unilateral e reducionista

e a promoção e proteção da dignidade de todas as pessoas e em todos os lugares". (p. 39)

${ }^{29}$ SARLET, Ingo Wolfgang. Dimensões da dignidade: ensaios de filosofia do direito e direito constitucional. Porto Alegre: Livraria do Advogado. 2013. p. 37. Nas palavras do autor, "[...] a título de sugestão, proposta pessoal de conceituação (jurídica) da dignidade da pessoa humana que, além de abranger (mas não restringir) a vedação da coisificação e, portanto, degradação da pessoa por conta da tradicional fórmula-objeto, busca reunir a

dupla perspectiva ontológica e instrumental referida, procura destacar tanto a sua necessária faceta intersubjetiva e, portanto, relacional quando a sua dimensão simultaneamente negativa (defensiva) e positiva (prestacional)."
}

(p.36).

${ }^{30}$ SARLET, Ingo Wolfgang Dignidade (da pessoa) humana e direitos fundamentais na Constituição Federal de 1988. Porto Alegre: Livraria do Advogado, 2015. p. 82; SARLET, Ingo Wolfgang A eficácia dos direitos fundamentais. Porto Alegre: Livraria do Advogado, 2015. p. 102. Acrescenta que "[...] cumpre salientar que a dignidade, como qualidade intrínseca da pessoa humana, é algo que simplesmente existe, sendo irrenunciável e inalienável, na medida em que constitui elemento que qualifica o ser humano como tal e dele não pode ser destacado, de tal sorte que não se pode cogitar na possibilidade de determinada pessoa ser titular de uma pretensão que lhe seja concedida a dignidade". (p. 102) 
logo da história da humanidade e o sustentáculo do ordenamento jurídico brasileiro - princípio.

\section{O FUNDAMENTO DA DIGNIDADE DA PESSOA E SUA EFICÁCIA NO ÂMBITO DO DIREITO PRIVADO}

A dignidade ${ }^{31}$ da pessoa humana é regulamentada tanto pelos direitos humanos quanto pelos direitos fundamentais, pois traduz o valor a ser preservado e resguardado por todos para que viabilize o desenvolvimento de forma integral e integrada da pessoa.

Nos ensinamentos Heinrich Hubmann, a dignidade humana ${ }^{32}$ indica que o lugar do ser humano no universo se dá em razão de sua estrutura espiritual e dotado de dons que lhe permitem reconhecer a sua humanidade pela mente consciente e pelo espírito objetivo e objetivado.

De acordo com Rosa Maria de Andrade Nery, o princípio da dignidade da pessoa humana é reflexo de visões culturais, é a razão de ser do Direito e prestigia a liberdade e a autonomia privada. Nas palavras dos autores:

Ele se bastaria sozinho para estruturar o sistema jurídico. Uma ciência que não se presta para prover a sociedade de tudo quanto é necessário para permitir o desenvolvimento integral do homem, que não se presta para colocar o sistema a favor da dignidade humana, que não se presta para servir ao homem, permitindo-lhe atingir seus anseios mais secretos, não pode dizer Ciência do Direito. Os antigos já diziam que todo direito é constituído bominum causa (fr. D.1.5). Comprometer-se com a dignidade do ser humano é comprometer-se com sua vida e com sua liberdade [...]. E o princípio da dignidade humana é o princípio fundamental do direito. É o primeiro. O mais importante. Como não poderia deixar de ser, é o princípio mais importante do Direito Privado e é o que rege todos os outros princípios. ${ }^{33}$ (grifos da autora)

\footnotetext{
${ }^{31}$ De Plácido e Silva. Vocabulário jurídico. Rio de Janeiro: Forense. 2002. p. 267. O termo dignidade "[...] deriva do latim dignitas (virtude, honra, consideração), em regra se entende a qualidade moral, que possuída por uma pessoa, serve de base ao próprio respeito em que é tida."

${ }^{32}$ HUBMANN, Heinrich. Das Persönlichkeitsrecht. Köln: Böhlau, 1967. p. 59-60. "Die würde des Menschen liegt in seiner Aufgabe, die er auch verfehlen kann. Er muss die geistige Anlage, in der sein Menschentum begründetist, erst zum Geist bilden und zweiten: zum bewusst Geist, zum objektiven Geist und zum objektivierten Geist".

${ }^{33}$ NERY, Rosa Maria de Andrade. Instituições de direito civil: parte geral. v. I, t. II. São Paulo: RT, 2015. p. 36.
} 
Do mesmo modo, Cármem Lúcia Antunes Rocha qualifica o princípio da dignidade da pessoa humana como valor fundante do sistema jurídico e coração do patrimônio jurídico-moral da pessoa humana. Nesse sentido, apresenta que

o princípio da dignidade da pessoa humana tornou-se, então, valor fundante do sistema no qual se alberga, como espinha dorsal da elaboração normativa, exatamente os direitos fundamentais do homem. Aquele princípio converteu-se, pois, no coração do patrimônio jurídico-moral da pessoa humana estampado nos direitos fundamentais acolhidos e assegurados na forma posta no sistema constitucional. ${ }^{34}$ (grifo meu)

Robert Alexy assevera que valor e princípio estão intimamente ligados, mas a partir dos conceitos deontológicos, axiológicos e antropológicos propostos por von Wright, estabelece-se a diferença decisiva entre eles. O valor está atrelado ao caráter axiológico e expressa juízo classificatório, comparativo ou métrico entre determinados objetos. O princípio possui caráter deontológico e estabelece mandamentos de natureza obrigatória, ou seja, o dever ser. ${ }^{35}$

No escólio de Humberto Ávila, os princípios

[...] são normas imediatamente finalísticas, primariamente prospectivas e com pretensão de complementaridade e de parcialidade, para cuja aplicação se demanda uma avaliação da correlação entre

\footnotetext{
${ }^{34}$ ROCHA, Cármem Lúcia Antunes. O princípio da dignidade da pessoa humana e a exclusão social. Disponível em http://egov.ufsc.br/portal/sites/default/files/anexos/32229-38415-1-PB.pdf. Acesso em 28 fev. 2013. Acrescenta a autora que "A constitucionalização do princípio da dignidade da pessoa humana não retrata apenas uma modificação parcial dos textos fundamentais dos Estados contemporâneos. Antes, traduz-se ali um novo momento do conteúdo do Direito, o qual tem a sua vertente no valor supremo da pessoa humana considerada em sua dignidade incontornável, inquestionável e impositiva, e uma nova concepção de Constituição, pois a partir do acolhimento daquele valor tornado princípio em seu sistema de normas fundamentais, mudou-se o modelo jurídicoconstitucional que passa, então, de um paradigma de preceitos, antes vigente, para um figurino normativo de princípios".

${ }^{35}$ ALEXY, Robert. Teoria dos direitos fundamentais. São Paulo: Malheiros, 2015. p. 144-153. Nas palavras do autor, "A diferença entre princípios e valores é reduzida, assim, a um ponto. Aquilo que, no modelo de valores, é prima facie o melhor e, no modelo de princípios, prima facie devido; e aquilo que é no modelo de valores, definitivamente o melhor é, no modelo de princípios, definitivamente devido". (p. 153); ÁVILA, Humberto. Teoria dos princípios: da definição à aplicação dos princípios. São Paulo: Malheiros, 2005. p. 72.
} 
o estado de coisas a ser promovido e os efeitos decorrentes da conduta havida como necessária à sua promoção. ${ }^{36}$

A par dessa constatação, a dignidade da pessoa humana não é apenas valor, mas também princípio que norteia todo o sistema jurídico de caráter deontológico e natureza obrigatória. Afasta-se a ideia de que a dignidade da pessoa humana tem feição abstrata ou ideal ou, ainda, seja somente um valor superior.

A dignidade da pessoa humana é princípio constitucional estruturante e fundamento do Estado Democrático de Direito, conforme artigo $1^{\circ}$, III da Constituição Federal de 1988 dotado de eficácia jurídica. E compete ao Estado garantir e promover a dignidade das pessoas, seja pelo dever de abstenção, pelo dever de respeitar, seja pelo dever de efetivar e proteger a dignidade da pessoa.

A concretização do princípio da dignidade da pessoa humana compete aos órgãos

estatais em todas as esferas de atuação do poder legislativo, executivo ou judiciário, nos âmbitos municipal, estadual ou federal.

Por tal motivo, o princípio da dignidade da pessoa humana está disposto não somente no artigo $1^{\circ}$, III da Constituição Federal, mas também no artigo 170, caput, ao assegurar a todos a existência digna, conforme os ditames da justiça social, como finalidade da ordem econômica fundada na valorização do trabalho e na livre iniciativa. Está disposto também no artigo $226, \S 7^{\circ}$, ao estabelecer como fundamento do planejamento familiar a dignidade da pessoa humana e a paternidade responsável e atribuir ao Estado a tarefa de propiciar recursos educacionais e científicos para o exercício desse direito. No artigo 227, caput atribui à família, à sociedade e ao Estado o dever de assegurar, com absoluta prioridade, à criança, ao adolescente e ao jovem o direito à dignidade e colocá-los a salvo de toda forma de negligência, discriminação, violência, crueldade e opressão. E no art. 230, impõe-se à família, à sociedade e ao Estado o dever de amparar as pessoas idosas, bem como defender a sua dignidade e seu bem-estar.

Desse modo, o princípio da dignidade da pessoa humana está previsto, expressamente, no ordenamento jurídico brasileiro como fundamento da República Federativa do Brasil e em outros subprincípios. A

\footnotetext{
${ }^{36}$ ÁVILA, Humberto. Teoria dos princípios: da definição à aplicação dos princípios. São Paulo: Malheiros, 2005. p. 70. O autor salienta que a "[...] a positivação de princípios implica a obrigatoriedade da adoção de comportamentos necessários à sua realização". (p.71)
} 
dignidade da pessoa humana adquire o status jurídico normativo; todavia não está elencada no art. $5^{\circ}$ da Constituição Federal.

A par dessa constatação, faz-se também necessário identificar como se efetiva a eficácia dos princípios no sistema jurídico. Neste artigo interessa, especificamente, a eficácia do princípio da dignidade da pessoa humana no âmbito do direito privado.

A análise dessa identificação é realizada pela eficácia dos princípios no sistema jurídico, - eficácia externa e eficácia interna, explicitadas por Humberto Ávila ${ }^{37}$ - bem como pela funcionalidade técnica, abordada por Rosa Maria de Andrade Nery. ${ }^{38}$

No tocante à eficácia dos princípios no sistema jurídico, Humberto Ávila explicita que ela pode ser externa ou interna. A eficácia externa pode ser subjetiva ou objetiva. Esta atua sobre a compreensão dos próprios fatos (exame de pertinência) e provas (exame de valoração), pois se interpreta, simultaneamente, o fato de acordo com a norma e a norma de acordo com o fato. A eficácia externa subjetiva se relaciona aos sujeitos atingidos pela eficácia dos princípios. ${ }^{39}$

A eficácia interna envolve a atuação de normas sobre outras normas do mesmo sistema jurídico com o intuito de definir o seu sentido e o seu alcance; subdivide-se em direta ou indireta. No presente trabalho, é relevante a eficácia interna dos princípios, especialmente, o princípio da dignidade da pessoa humana. A eficácia interna direta revela a função integrativa dos princípios, pois agrega elementos não previstos em subprincípios ou em regras com o escopo de garantir a efetivação daquele direito. $^{40}$

Já na eficácia interna indireta, os princípios assumem várias funções na tarefa de intermediação ou interposição, as quais classificamse em: (i) definitória, quando delimita o alcance de princípio axiologicamente superior; (ii) interpretativa, quando restringe ou amplia o sentido de normas construídas, a partir de textos normativos e (iii) bloqueadora,

\footnotetext{
${ }^{37}$ ÁVILA, Humberto. Teoria dos princípios: da definição à aplicação dos princípios. São Paulo: Malheiros, 2005. p. 78-86.

${ }^{38}$ NERY, Rosa Maria de Andrade. Instituições de direito civil: parte geral. v. I, t. II. São Paulo: RT, 2015. p. 531-535.

39 ÁVILA, Humberto. Teoria dos princípios: da definição à aplicação dos princípios. São Paulo: Malheiros, 2005. p. 80-82.

40 ibidem., p. 78.
} 
quando afasta elementos, expressamente, previstos em razão da incompatibilidade com o estado ideal de coisas a ser promovido. ${ }^{41}$

O princípio da dignidade da pessoa humana, na concepção de Humberto Ávila, é um sobreprincípio que exerce a função interpretativa e bloqueadora do princípio no tocante à eficácia interna direta, mas não exerce a função integrativa e definitória. Para o autor, o sobreprincípio desempenha a função rearticuladora, pois há a interação entre vários elementos que compõem o estado ideal das coisas. ${ }^{42}$

Com isso, dá-se um novo e diferente significado suficiente para reconhecer a possibilidade jurídica do pedido formulado pelo jurisdicionado em ação de retificação de registro civil, bem como para e autorizar a modificação do prenome e a alteração do sexo indicados no registro civil. $^{43}$

No escólio de Rosa Maria de Andrade Nery, a eficácia civil dos direitos fundamentais é analisada pela funcionalidade técnica ${ }^{44}$ para proporcionar a melhor solução ao problema apresentado concretamente. Sob esse prisma, ela propõe enfrentar os tradicionais elementos do direito privado - sujeitos / bens / atos - cercados por categorias que denomina

41 ibidem., p. 78-90.

42 ÁVILA, Humberto. Teoria dos princípios: da definição à aplicação dos princípios. São Paulo: Malheiros, 2005. p. 80.

${ }^{43}$ SUPERIOR TRIBUNAL DE JUSTIÇA. REsp.n. 737.993 - MG (2005/0048606-4). Jul. em 10/11/2009. Rel. Min. João Otávio de Noronha. DJe 18/12/2009. Ementa: REGISTRO PÚBLICO. MUDANÇA DE SEXO. EXAME DE MATÉRIA CONSTITUCIONAL. IMPOSSIBILIDADE DE EXAME NA VIA DO RECURSO ESPECIAL. AUSÊNCIA DE PREQUESTIONAMENTO. SUMULA N. 211/STJ. REGISTRO CIVIL. ALTERAÇÃO DO PRENOME E DO SEXO. DECISÃO JUDICIAL. AVERBAÇÃO. LIVRO CARTORÁRIO. 1. Refoge à competência outorgada ao Superior Tribunal de Justiça apreciar, em sede de recurso especial, a interpretação de normas e princípios de natureza constitucional. 2. Aplica-se o óbice previsto na Súmula n. 211/STJ quando a questão suscitada no recurso especial, não obstante a oposição de embargos declaratórios, não foi apreciada pela Corte $a$ quo. 3. O acesso à via excepcional, nos casos em que o Tribunal a quo, a despeito da oposição de embargos de declaração, não regulariza a omissão apontada, depende da veiculação, nas razões do recurso especial, de ofensa ao art. 535 do CPC. 4 . A interpretação conjugada dos arts. 55 e 58 da Lei n. 6.015/73 confere amparo legal para que transexual operado obtenha autorização judicial para a alteração de seu prenome, substituindo-o por apelido público e notório pelo qual é conhecido no meio em que vive. 5. Não entender juridicamente possível o pedido formulado na exordial significa postergar o exercício do direito à identidade pessoal e subtrair do indivíduo a prerrogativa de adequar o registro do sexo à sua nova condição física, impedindo, assim, a sua integração na sociedade. 6. No livro cartorário, deve ficar averbado, à margem do registro de prenome e de sexo, que as modificações procedidas decorreram de decisão judicial. 7. Recurso especial conhecido em parte e provido.

${ }^{44}$ NERY, Rosa Maria de Andrade. Instituições de direito civil: parte geral. v. I, t. II. São Paulo: RT, 2015. p.531-535. A autora identifica que a eficácia civil dos direitos fundamentais em outra abordagem pode ser analisada pela penetração dogmática direta ou indireta ou por seu alcance material. 
valores, princípios, cláusulas gerais e padrões. Fundamenta que as categorias contêm uma ligação funcional ${ }^{45}$ e guardam entre si uma hierárquica instrumentalidade.

Para ilustrar a funcionalidade técnica, a autora explica que o ponto de partida é o respeito pela vida, por ser o valor fundamental da ciência jurídica. Esse valor inspira o princípio fundamental que é o da dignidade do ser humano que se torna princípio de direito privado apto para inspirar a conduta daqueles que realizam os atos e os negócios jurídicos. Essas condutas estabelecem as cláusulas gerais e, com isso, fixam os critérios gerais de condutas que não podem ser afastados pelo sujeito. ${ }^{46}$

De outro norte, Rosa Maria de Andrade Nery considera que a eficácia civil dos direitos fundamentais é o

[...] fenômeno de as disciplinas do direito privado respeitarem os direitos fundamentais insculpidos na Constituição e todos os regramentos que ela adota, como maneira de realização do bem comum e de produção de efeitos compatíveis com o respeito aos direitos fundamentais, essenciais à preservação da dignidade do ser humano. ${ }^{47}$

O fundamento do princípio da dignidade da pessoa humana e sua eficácia no âmbito do direito privado se justificam na perspectiva teleológica, pois as normas de direito privado estão vinculadas, de forma imediata, aos direitos fundamentais.

O sistema jurídico do Código Civil brasileiro é dotado de mobilidade para alcançar os valores essenciais da humanidade do ser, sob o fundamento da dignidade da pessoa humana e dos valores sociais do trabalho; o objetivo da prevalência dos direitos humanos e o princípio da igualdade, previstos nos artigos $1^{\circ}$, III e IV; $4^{\circ}$, II e $5^{\circ}$, caput da Constituição Federal de 1988, respectivamente.

A atualização normativa civilista se viabiliza pela mobilidade que agrega os valores e os princípios estruturantes do Código Civil, a saber, a eticidade, a socialidade e a operabilidade que se opõem ao forma-

\footnotetext{
${ }^{45}$ ibidem., p.531-535. Para a autora, a ligação funcional é visualizada da seguinte maneira "[...] os valores funcionam como idealidades civis que inspiram a ordem jurídica; os princípios são a assunção em forma de preceitos desses valores; os padrões valorativos são a identificação de critérios preliminares de conduta; os padrões valorativos são a medida social da aplicação daqueles critérios". (p.533)

${ }^{46}$ NERY, Rosa Maria de Andrade. Instituições de direito civil: parte geral. v. I, t. II. São Paulo: RT, 2015. p.531-535.

${ }^{47}$ ibidem., p. 532.
} 
lismo jurídico, ao individualismo e à ineficácia de alguns institutos jurídicos do Código Civil de 1916.

\section{CONSIDERAÇÕES FINAIS}

O princípio da dignidade da pessoa humana em sede constitucional (art. $1^{\circ}$, III da $\mathrm{CF} / 88$ ) retrata o valor supremo da pessoa humana considerada em sua dignidade e condiciona a sua observância por se tratar de princípio que norteia todo o sistema jurídico de caráter deontológico e natureza obrigatória. E compete ao Estado garantir e promover a dignidade das pessoas, seja pelo dever de abstenção, pelo dever de respeito, seja pelo dever de proteção através de medidas nas dimensões negativa(limite) e prestacional (tarefa) para que a pessoa possa se desenvolver de forma integral e integrada.

Depreende-se da análise dos ensinamentos de Jorge Reis Novais e Ingo Wolfgang Sarlet que a dignidade da pessoa humana tem como elemento nuclear a liberdade, a autonomia, o bem-estar e a autodeterminação. Admitem os autores que qualquer conduta, comportamento ou medida de caráter de exclusão, alienação, incapacitação ou subjugação devem ser afastadas ou repelidas pela própria pessoa, pela família, pela sociedade ou pelo Estado.

A eficácia do princípio da dignidade da pessoa no âmbito do direito privado se justifica na perspectiva teleológica, pois as normas de direito privado estão vinculadas, de forma imediata, aos direitos fundamentais.

Desse modo, observa-se que presente o elemento nuclear do fundamento da dignidade da pessoa humana potencializa o reconhecimento e respeito para garantir a sua intangibilidade e ao mesmo tempo impede a sua banalização.

\section{REFERÊNCIAS BIBLIOGRÁFICAS}

ALEXY, Robert. Teoria dos direitos fundamentais. São Paulo: Malheiros, 2015.

ÁVILA, Humberto. Teoria dos princípios: da definição à aplicação dos princípios. São Paulo: Malheiros, 2005.

De Plácido e Silva. Vocabulário jurídico. Rio de Janeiro: Forense. 2002. 
DECLARAÇÃO DAS NAÇÕES UNIDAS. Nisponível em http://www.planalto.gov.br/ccivil_03/decreto/1930-1949/d19841.htm. Acesso em 27 fev. 2017.

DECLARAÇÃO UNIVERSAL DOS DIREITOS DO HOMEM. Disponível em http://www.dhnet.org.br/direitos/deconu/textos/integra.htm. Acesso em 27 fev. 2017.

FRANÇA, Limongi R. Enciclopédia Saraiva. v. 25. São Paulo: Saraiva, 1977.

HUBMANN, Heinrich. Das Persönlichkeitsrecht. Köln: Böhlau, 1967.

NERY, Rosa Maria de Andrade; NERY, Nelson. Instituições de direito civil: parte geral. v. I, t. I. São Paulo: RT, 2015.

. Instituições de direito civil: parte geral. v. I, t. II. São Paulo: RT, 2015.

NOVAIS, JORGE REIS. A dignidade da pessoa humana: dignidade e direitos fundamentais. v. I. Coimbra: Almedina. 2016.

. A dignidade da pessoa humana: dignidade e inconstitucionalidade. v. II. Coimbra: Almedina. 2016.

RADBRUCH, Gustav. Introdução à filosofia do direito. São Paulo: Método. 2014.

REALE, Miguel. História do novo Código Civil. São Paulo: RT, 2005.

ROCHA, Cármem Lúcia Antunes. O princípio da dignidade da pessoa humana e a exclusão social. Disponível em <http://egov.ufsc.br/portal/sites/default/files/anexos/32229-38415-1PB.pdf>. Acesso em 28 fev. 2013.

SARLET, Ingo Wolfgang. Dimensões da dignidade: ensaios de filosofia do direito e direito constitucional. Porto Alegre: Livraria do Advogado. 2013.

. A eficácia dos direitos fundamentais. Porto Alegre: Livraria do Advogado, 2015.

Dignidade (da Pessoa) humana e direitos fundamentais na Constituição Federal de 1988. Porto Alegre: Livraria do Advogado. 2015.

SUPERIOR TRIBUNAL DE JUSTIÇA. REsp .n. 737.993 - MG (2005/0048606-4). Jul. em 10/11/2009. Rel. Min. João Otávio de Noronha. DJe 18/12/2009. 